\title{
Sıradanlaşmaya Karşı Direniş: The Wooster Group
}

\author{
Dr. Elif Baş \\ Bahçeşehir Üniversitesi Ĕ̆itim Bilimleri Fakültesi \\ Ingilizce Öğretmenliği Bölümü \\ elif.bas@eas.bau.edu.tr
}

Öz

Yaklaşık otuz beş yıldır çalışmalarını sürdüren The Wooster Group, dünyanın en iddialı ve radikal tiyatro topluluklarından biridir. Bu çalışmada, Sakonnet Point, Rumstick Road ve L.S.D. (... Just the High Points...) oyunlarından yola çıkarak The Wooster Group'un merkez kavramını nasıl sorunsallaştırdı ğı, prova sürecinin oyunun bir parçası haline nasıl getirildiği ve izleyiciye yeni anlamlar ürettiren çok anlamı yapının nasıl oluşturulduğu incelenir. Metinlerde yatan çelişkileri ya da ideolojileri ortaya koymak için The Wooster Group'un metinlere nasıl yaklaştığı ele alınır. Son olarak, grubun oyuncu ve karakter arasındaki ilişkiye nasıl yeni bir bakış açısı getirdiği Willem Dafoe üzerinden örneklendirilir. Özetle, The Wooster Group'un pek çok açıdan Jacques Derrida'nın yapısöküm yöntemine sahnede nasıl hayat verdiği ortaya konur.

Anahtar Kelimeler: The Wooster Group, yapısöküm, avangart tiyatro, deneysel tiyatro.

\section{Organized Resistance against Norms: The Wooster Group}

\section{Abstract}

The Wooster Group has been one of the most radical theatre companies of the world in the past thirty five years. This article examines how The Wooster Group abandons the idea of establishing a center, and how they work as an ensemble in creating the text. It also demonstrates how the rehearsal process becomes the text itself and how their performances generate multiple meanings. Moreover, it explores the ways the group deciphers the discrepancies that permeate the text. Finally it takes a look at their idea of acting, the relationship between the actor and the character through Willem Dafoe. Overall the article exemplifies how their performances reflect the deconstructionist ideas of Jacques Derrida.

Keywords: The Wooster Group, deconstruction, avant-garde theatre, experimental theatre. 


\section{GíRIŞ}

1980'li yılların başından beri çalışmalarını sürdüren The Wooster Group, çağdaş Amerikan tiyatrosunda çığır açan dünya tiyatrosunun en iddialı topluluklarından biridir. Avangart birçok çalışmaya imza atan ekip bu başarısını kendisine özgü güçlü bir tiyatro dili oluşturarak kazanmıştır. Topluluğun kurucuları olan Elizabeth LeCompte ve Spalding Gray çalışmalarına ilk olarak avangart tiyatronun öncülerinden Richard Schechner tarafından kurulan The Performance Group ile başlar. LeCompte, 1970 yllında The Performance Group'a katılır ve 1974'ten itibaren de grupta yönetmen yardımcllı̆̆ yapmaya başlar. Bu süre içerisinde çıraklığını atlattığını ifade eden LeCompte bir süre sonra bazı konulardan rahatsızlık duymaya başlar. Schechner'ın mizansenini fazla sembolik, oyunculuğa yaklaşımını fazla psikoanalitik bulurken, kullandıkları materyallerin ise yeterince süzgeçten geçirilmediğini düşünür (Savran 1988: 3). Özellikle Schechner'ın oyunculuk yöntemini eleştirir: "Richard bir duygunun aktarlması için o duygunun oyuncu tarafindan hissedilmesi gerektiğini düşünüyordu. Oyuncularm bu duygulan seyirci karşısında hissetmelerini istiyordu. Bense bir duyguyu aktarmak için illaki o duygunun sahnede hissedilmesi gerektiğini düşünmüyordum"1 (Champagne 1981: 20). Bu sebeple LeCompte 1975 yılında Spalding Gray ile Schechner'dan bağımsız Sakonnet Point adlı ilk çalışmasına başlar. Ekip, The Wooster Group adını 1980 yılında kullanmaya başlamış olsa da Sakonnet Point sonrası sahnelenen oyunlar The Wooster Group'a atfedilir. O dönem görselliğe odaklanan Robert Wilson, Richard Foreman, JoAnne Akalaitis, LeeBreuer, ve Ruth Maleczech gibi yönetmenlerin aksine LeCompte tiyatroda farklı bir dil arayışına girer. Grotowski'nin oyuncuyu merkeze alan teknolojiden uzak tavrını sinırlayıcı bulur: "Her şey merkezdedir! Neden sadece oyuncu merkezde olsun ki? [...] Kendimi kısıtlamak istemedim..." (Dunkelberg 2005: 44) Bu düşüncelerle yola çıkan LeCompte topluluğa önemli isimler dahil eder. Temel kadro arasında Spalding Gray, Peyton Smith, Kate Valk, Ron Vawter, Jim Clayburgh ve Willem Dafoe bulunur. Yönetmenliği genellikle LeCompte üstlenirken, seyirciler ekibin deneysel serüvenleriyle New York'un Soho bölgesinde bulunan The Performing Garage' da buluşur.

$\mathrm{Bu}$ çalışma, The Wooster Group'un oyunlarında merkez kavramını nasıl yıktığını, performanslarının her oyuncunun katkısı olacak şekilde bilinçaltı ve içgüdüsel kaynaklarla nasıl evrildiğini inceler. Metnin içinde barındırdığı çelişkileri ortaya çıkarmak için metinlere nasıl yaklaştıklarını ve bu yaklaşımlarının özellikle klasik metinleri kullanırken onlara ne gibi zorluklar yaşattı̆̆ını ortaya koyar. Prova sürecinin oyuna nasıl dahil edildiği ve izleyiciye yeni anlamlar ürettiren çok anlamı yapının nasıl oluşturulduğu Sakonnet Point, Rumstick Road ve L.S.D. (... Just the High Points....) oyunlarryla örneklendirilir. Son olarak, metni odak noktası olmaktan çıkaran topluluğun, oyuncu ve karakter arasındaki ilişkiyi ne şekilde değiştirdiği Willem Dafoe üzerinden anlatılır. Özetle, The Wooster Group'un pek çok anlamda Jacques Derrida'nın yapısöküm yöntemini yaratıcı süreçlerinde nasıl kullandıkları ortaya konur.

${ }^{1}$ Aksi belirtilmedikçe çeviriler yazara aittir. 


\section{Topluluğun Çalışmaları}

Topluluğun ilk çalışmaları, Sakonnet Point (1975), Rumstick Road (1977) ve Nayatt School (1978) oyunlarından oluşan Rhode Island üçlemesidir. Otobiyografiden faydalanarak ortaya çıkan bu oyunlar isimlerini Spalding Gray'in çocukluğunu geçirdiği yerlerden alır. Üçleme, hem oyuncuların daha önce The Performance Group ile yaptıkları çalışmalardan hem de o güne kadar çağdaş Amerikan tiyatrosunun sergilediği denemelerden radikal biçimde farklıdır. Altı bölümden oluşan Sakonnet Point (uçak, çocuk, ev, fan, battaniye, çarşaf), Spalding Gray'in bir erkek çocuk ve üç kadın ile olan ilişkisini anlatır. Oyun, Gray'in otobiyografisinden esinlenerek ortaya çıkmış olmasına rağmen, ekipteki diğer üyelerin katkılarıyla biçimlendirilmiş ve LeCompte'un yaratıcı vizyonu doğrultusunda son şeklini almıştır. LeCompte bu süreci şu şekilde anlatır:

Spalding benim çizeceğim resim için poz verir. Libby, Ron, Bruce (Porter) ve diğer grup üyeleri bazen bana yardim ederler bazense Spalding ile resme dahil olurlar. Ressam ile poz veren kişi arasında bir diyalog vardır. Ortaya çıkan resim, yani bu resmin yarattığı kişi, poz veren kişinin kendini algılayışı ile ressamın onu nasıl gördüğ̈̈nün birleşimidir. Hem ressam hem de resmedilen biten tabloda kendisini algılayabiliyorsa sonuç mükemmel bir işbirliğidir (Bierman 1979: 13-14).

The Wooster Group, önce içe, yaratının kaynağı olan bireye yönelir sonrasında ise kolektif bir yol izler. Kişilerin ya da objelerin bu şekilde ham madde gibi metin yaratma sürecinde kullanılması yeni bir durumdur. Ne var ki bu ham madde, ortaya çıan sonucun sadece küçük bir parçasıdır. Gray'e göre “Çoğu kez seyircinin gördüğ̈̈ şey kendi zihinlerinin bir yansıması, kendi izdüşümleridir" (Gray 1979: 36). Bunun temel sebeplerinden biri de oyunun geleneksel bir yapıya sahip olmayışı ve izleyiciye belirli bir anlam ya da mesaj dayatılmayışıdır. Öyle ki prova esnasında herhangi bir sahnenin; giriş, gelişme ve sonuçtan oluştuğu fark edilirse, o sahne tekrar düzenlenir geleneksel yapı hemen parçalanır (Aronson 1975: 34). Böylece The Wooster Group'un oyunlarında geleneksel yapı mutlak hâkimiyetini kaybeder.

Sakonnet Point, belli "aktiviteler" üzerinden giden doğaçlama çalışmalarla oluşturulur. Örneğin "yontma" ya da "oyuncak askerlerle oynama" gibi basit aktivitelerden yola çıkılır. Gray bunun için uygun ortamı yaratırken, Elizabeth LeCompte yönetmen olarak hangi aktivitelerin seçildiğine ve bunların nasıl şekillendirilmesi gerektiğine karar verir. $\mathrm{Bu}$ aktiviteler sahnenin üç ya da dört farklı bölgesinde eşzamanlı sahnelenir. Müzik ya da ses, aktivite ile senkronize olarak başlayıp bitmez. Bu yüzden izleyicinin odak noktası sürekli olarak değişim halindedir. Düzenli şekilde yükselen tansiyon gerekirse aksiyon barındıran sahnelerde bile bilinçli olarak sekteye uğratılabilir (Aronson 1975: 33). Anlatımda diyaloğa neredeyse hiç yer verilmez. Buna rağmen topluluğun bu tür çalışmaları geleneksel anlamda mim ya da dans performansı olarak değerlendirilemez. Gray bu süreci yeni jestlerin ve bireysel mimiklerin keşfi olarak nitelendirir (Gray 1978: 87). Dolayısıyla performansları; hareket, jest ve mekân arasındaki koreografiye dayanır. Örneğin sahnelerden biri, Gray ve bir kadın arasında geçer. Bir süre sadece çadır aydınlatılır. Sonra ışık taburede oturan LeCompte'u aydınlatır. İkisi, bir süre nasıl çorap çıkarılması gerektiğiyle ilgili sözsüz bir tartı̧̧maya girer. Sonra sırayla tabureye otururlar ve bu sefer çorabın nasıl çıkarılması gerektiğini göstererek anlatırlar. Bu sahne, kadının kırmızı bir duş başlığını Gray'e doğru sallayıp ağzına sokması ve düşerek yere yatmasıyla sonlanır. Kırmızı duş başlığı ağzında köpüren kan izlenimi verir. Gray kadına bakar ve elleriyle kadının gözlerini kapatır. Işık kararır (Bierman 1979: 17). Bir saatlik performans boyunca objeler boşlukta dans 
ediyormuşçasına etrafta süzülür. "Objeler illüstrasyon ya da dekorasyon amaçl kullanılmaz. Çoğunun belli bir işlevi vardır. Objelere karşı saygım var, ancak objelerin kullanılabilmesi için belli bir geçmişe sahip olmalar gerekir" der LeCompte (Champagne 1981: 23). Sakonnet Point oyununda kullanılan objelerden bazıları üçlemenin diğer oyunlarında da kullanılır. Sahnelenen her yeni oyunda, daha önceki performanslarda kullanılan her türlü kostüm ve motif tekrar kullanılabilir. Örneğin, Rumstick Road için kullanılmış olan zemin planı, biraz değiştirilip farklı bir açıdan Nayatt School'da kullanılmış ya da Rumstick Road'daki doktor muayenesi, diğer bir oyunda komedi unsuru olan göğüs muayenesi sahnesine dönüşmüştür. Bu durum tek bir obje ya da motifin başka bir oyunda bağımsız olarak kullanılması olarak algilanmamalıdır. Bu yolla her oyun bir öncekine, hatta birden fazla oyuna gönderme yapabilir ve dikkatle incelendiğinde her oyun oldukça karmaşık anlam ilişkileri barındırır. $\mathrm{O}$ güne kadar, diğer tiyatro toplulukları da kendi geçmişlerini bir sonraki oyuna taşımıştır; ancak The Wooster Group'un aksine her çalışmaya ayrı bir proje gözüyle bakılmıştır. Oysa The Wooster Group, tiyatro tarihinde görülmemiş bir şey yapmış ve bir performanstan diğerine uzanan, sürekli etkileşim içinde olan ve kendisine gönderme yapan eserler ortaya koymuştur (Aronson 2000:152).

Topluluğun otobiyografiden faydalanarak yaptığı çalışmalar, medyada özel hayata ilişkin soruları gündeme getirmiştir. Örneğin 1977'de sahnelenen Rumstick Road, üçlemenin diğer oyunları gibi Spalding Gray'in hayatına dayanır. Kullanılan materyaller arasında Gray'in babası ve büyükanneleriyle yaptığı görüşmelerin ses kayıtları, annesinin psikiyatristiyle yaptığı görüşme kaydı bulunur. Gray, bu görüşmelerde annesinin intiharının onları nasıl etkilediğini sorar (Gray 1979: 38). Ne var ki psikiyatristle yapılan telefon konuşmasının izin alınmadan kullanılması tartışmalara sebep olur. Gray'in annesi bu konuşmadan kısa süre önce 1967 yılında intihar etmiştir. Gray bu kayıtları tekrar tekrar dinleyip bunlar üzerine düşündüğünden bahseder. Bu süreci şöyle anlatır: "İntihar gibi anlam veremediğim bir davranıştan anlaml bir bütün oluşturmaya çalışıyordum. Belki de, yeniden oluşturacağım bu eserle annemin kaotik dünyasın düzeltebileceğimi umuyordum" (Gray 1979: 38).

Kişisel kaynakların kullanımına rağmen Spalding Gray oyunu belgesel olarak nitelendirmez: "Oyunun kaynağı ben olmama rağmen sonuç tüm katılımcların düşünsel kolektif davranışlarının ürünüdür. Neticede bir grup otobiyografisi oluşturduk" (Gray 1979: 34). Prova sürecinde orijinal materyale ekibin verdiği tepkiler gözlemlenir ve doğaçlama çalışmalar yapılır. Gray yukarıdaki sözleriyle aslında bu çalışmaların göz ardı edilmemesi gerektiğini vurgular. Kayıtların kullanımı bu sebeple topluluk için sorun teşkil etmez çünkü kayıtlar onlar için sadece ham bir materyaldir, ortaya çıkan çalışma ise farklı anlam ilişkileri barındıran kolektif bir çalışmanın ürünüdür.

Rumstick Road, Sakonnet Point'e göre daha çok sözlü anlatım içerir. Örneğin iki oyuncu çarşaflarla kaplı olan sandalyelere oturur. İkisini ayıran masanın üzerinde bir ses kayıt cihazı bulunmaktadır. Oyuncular, Gray ve babası arasında geçen konuşmayı dudaklarını oynatarak seslendirir. Gray daha sonra sahnenin diğer tarafına giderek annesinin psikiyatristi olan Dr. Henry Bradford ile olan telefon görüşmesini gerçekleştirir. Gray bu sefer canlı konuşurken doktorun sesi kayıt olarak verilir. Hemen sonrasında Gray büyükannesiyle konuşur. Yaşlı bir kadına dönüştürülmüş olan oyunculardan biri tekerlekli sandalyeyle sahneye girer. Diğer oyuncular da büyük abartılı jestlerle bu sahneye katılır. Oyun, Gray'in babasından 1966 yılında aldığı bir mektubu seyirciye okumasıyla biter (Bierman 1979: 22). Burada Gray'in birebir kendisini canlandırdığını düşünmek yanıltıcı olur. Gray'in kendi hakkındaki uzun monologları son derece içten ve samimidir. Ne var ki 
masada duran suyu ne zaman içtiği, ne zaman es verdiği bile daha önceden detaylı olarak çalışılmıştır. Karşımızda kendi kişiliği üzerine kurulmuş yeni bir karakter vardır. Gerçek Gray ile bu yeni karakter arasındaki fark bir çeşit yabancılaştırma efekti yaratır (Aronson 2000: 155). Gray oyunun gerçek hayatıyla olan bağını ve farkını şu şekilde dile getirir:

Rumstick Road annemin geçirdiği bunalımı sahneye koyduğum bir çalışma değildir, bu olay karşısında benim hissettiklerimi ifade etme çabası de değildir. Rumstick Road bambaşka bir şeydir. Bir çeşit sanat eseri, kendi başına var olan yepyeni bir şeydir. Ve eğer bu çalışmanın iyileştirici bir etkisi varsa bunun günah çıkarmakla değil SANAT icra etmekle ilgisi vardır. Annemin intihar edişi bu SANAT'ın sadece küçük bir parçasıdır. Nihayetinde, bu eser intiharla ilgili değildir, SANAT yapmakla ilgilidir (Gray 1979: 39).

Topluluk, Rhode Island üçlemesindeki gibi otobiyografik materyallerden faydalanmanın yanı sıra Arthur Miller, Eugene O'Neill, Thornton Wilder gibi yazarların klasik metinlerini de kendi sahne diliyle de buluşturur. LeCompte klasik eserlerdeki belli sahneleri, karakterleri, imgeleri ya da diyalogları oyuncularıyla değerlendirdikten sonra bunları Derrida'nın yapısöküm yöntemine benzer şekilde tekrar kurup şekillendirir. Bu süreçte, The Wooster Group metni toplumun kültürel bilinci olarak görür ve metne ham materyal gibi yaklaşır. LeCompte kullandıkları klasik metni masada duran bir eşyadan ya da oyuncuların jestinden farklı görmez. Topluluk, klasik metinden aldıkları parçaları başka metinlerle ya da dans, müzik gibi farklı dillerle birleştirerek yeni anlamlar üreten, klasik metnin içinde var olan anlamları sorgulayan yapımlara imza atar. Dolayısıyla elde ettikleri sonuç metinde yatan sosyal kodları ve önyargıları ortaya koyması bakımından Jacques Derrida'nın yapısöküm yönteminden farklı değildir.

Topluluğun klasik bir metin kullanarak hazırladıkları en çarpıcı ve tartışmalara en çok sebep olan oyunları L.S.D. (...Just the Hight Points...) olur. L.S.D. farkl kaynaklarm bir araya getirildiği dört bölümden oluşur. Arthur Miller'ın Cadı Kazanı gibi klasik bir metinle işe başlayan topluluk, Beat kuşağının eserlerini, Timothy Leary ve G. Gordon Liddy arasında geçen tartışmayı, Ann Rower ile yapılan röportajı bir araya getirip, müzik, dans ve videolarla oyuna canlılik kazandırır (Aronson, 1985:67). Oyun boyunca oyuncular kendilerine verilen metinleri mikrofondan yalın bir şekilde okurlar. Bu durum belgelerin bir araya getirilerek seyirciye aktarıldığı izlenimi yaratır. Burada oyuncunun materyale olan duygusal tepkisinden çok bilgi aktarımı ön plandadır. Öyle ki, Cadı Kazanı'nın şiddetli mahkeme sahnesinde bile duygusal bir çıkış söz konusu olmaz. Brecht'in yaklaşımı doğrultusunda "histeri" incelenmesi gereken bir olgu olarak sunulur (Savran 2007: 31). Genel olarak, bu gibi metinlerin seçiminde LeCompte oyunun konusundan ziyade "kelimelerin, imgelerin, seslerin ya da özel bă̆lantıların çarpıcı bir şekilde bir araya gelmesiyle" ilgilenir (Savran 2005: 27).

Oyunda birbirinden bağımsız öğeleri birleştiren bazı tematik bağlar olsa dahi, L.S.D.'deki bir çok şey aslında gelişigüzel ortaya çıkar. Oyuna hazırlık sürecinde yaşananlar oyun metninin parçası haline gelir. Örneğin LeCompte grubun bir provasını oyuncular halüsinasyona neden olan LSD ilacının etkisi altındayken kaydeder. Bunun sonucunda oyuncuların ilaç kullanıyormuş gibi davrandıkları bir sahneyi oyuna eklemeye karar verir. Buna benzer başka bir örnek ise oyunculardan Michael Kirby'nin topluluğun çıktığı bir turneye katılamamasıyla yaşanır. Bu sorunu çözmek için LeCompte, Kirby'nin sahnelerini videoya çeker ve tur esnasında Kirby yerine bu çekimler kullanılır. Daha sonra Kirby oyuna geri döner ancak eski kayıtlar sonraki temsillerde de gösterilmeye devam edilir. Böylece Kirby kendi görüntüsüyle etkileşime girer (Aronson 2000: 188). Görüldüğü gibi, 
kendiliğinden ortaya çıkan durumlar, oyuna şekil vermekle kalmaz oyunda önceden düşünülmemiş farklı anlamların üretilmesini sağlar.

Topluluğun bu özelliği, performanslarının en can alıcı noktası haline gelebiliyordu. Örneğin L.S.D'de, oyundaki siyahi karakter Tituba'yı yüzü siyaha boyanmış olarak oynayan oyuncu, başka bir sahnede beyaz olan Mary Warren karakterini canlandırır. Bu oyuncu, Mary olarak sahneye çıktığında yüzündeki siyah boyayı silmez. Bunun asıl sebebi makyajın silinmesi için yeteri kadar vaktin olmamasıdır (Aronson 2000: 189). Kendiliğinden gelişen bu sahne, diğer detaylarla bir araya geldiği zaman izleyiciyi; kimlik ve rrk gibi konularda düşünmeye iter. Diğer sahnelerde erkek oyuncuların mikrofonla konuşması kadınlara ise mikrofon verilmemesi, erkeklerin modern kıyafetler giymesi kadınların ise o dönemin kıyafetleriyle sahneye çıkması cinsel ayrımcılığa gönderme yapar. Philip Auslander'ın deyişiyle "L.S.D. Miller'ın oyununda pek de hafif olmayan cinsiyetçiliği gözler önüne serer." (1987: 27-28) Bahsi geçen bu detayların çoğu prova sürecinde doğal olarak ortaya çıkar. LeCompte, oyun metninin kendiliğinden nasıl oluştuğunu şöyle anlatır:

Metnin oluşumunu sağlayan tesadüfi olaylar yaşanır, buna sine qua non da diyebiliriz. İşte bu, başlangıç noktamızdır ve bu olay, metni oluşturur. Bu metinden kaçış imkansızdır. Diğgerleri nasıl oyun yazarlarının metinlerini kullanıyorsa ben de eylemi temel başlangı̧ noktam olarak alırm. Yok sayamam... Oyunla hiçbir bağlantısı olmayan bir olay bile olabilir bu. Ben buna şans oyunu gözüyle bakarım. Havaya bir dolu bozuk para atarsınız ve yere düştüklerinde oluşan şekli kullanmak zorundasınizdır. .." (Savran 1988: 51).

LeCompte bu sıra dışı yaklaşımını klasik metinlere uygulamaya çalıştığında zaman zaman ciddi sorunlarla uğraşmak zorunda kalır. L.S.D., Cadı Kazanı oyunundan sadece bir bölüm içermesine rağmen Arthur Miller, oyunun kendisinden izinsiz ve çarpıtılmış olarak kullanıldığı gerekçesiyle gruba dava açacağını bildirir. Miller oyununun bir parodiye çevrildiğini düşünür ve kaygılarını şu şekilde dile getirir: "Karşılaştığımız mesele çok basit. Oyunumun benim yazdığım ve tasarladığım şeklin dışında sahnelenmesini istemiyorum. . . İnsanların, onların hazırladıkları versiyonu izleyip oyunumu o şekilde yazmadığımı bilmemeleri beni rahatsız ediyor" (Rabkin 1985: 144). Arthur Miller gibi oyun yazarken tüm ayrıntıları düşünen bir yazar için bu geçerli bir açıklama olsa bile, konuyla ilgili farklı görüşler ortaya çıkar. Oyunun sahnelendiği 1984 yılında metinle metnin sahnelenmesi arasındaki ilişki akademik çevrelere konu olmaktan çıkar ve The New York Times gibi bir gazeteye "Oyun yazarlarının haksızlığa uğradığına kim karar verecek?" başlığıyla konu olur (Rabkin 1985: 142). Gerald Rabkin ise Arthur Miller'ın gerekçesiyle ilgili ilginç bir tespitte bulunur: "Oyunda, Cadı Kazanı Arthur Miller'ın iddia ettiği üzere 'gülünç bir parodi' şeklinde kullanılmış olsaydı, oyunun yasal olarak kullanılması mümkün olurdu çünkü anayasa hiciv yazarlarının bu hakkını korumaya öncelik vermektedir" (Rabkin, 1985:144). Rabkin işin farklı bir boyutuna işaret ederken Elizabeth LeCompte ise amaçlarını Miller'a anlatma çabasındadır. LeCompte'un Miller'a 30 Kasım 1983'te yazdığı mektupta oyunu niçin kullanmak istediklerini şöyle açıklar: "İroni ve yabancılaştırma efekti kullanarak Cadı Kazanı'nın politik, entelektüel ve duygusal yönlerini ortaya çıkarmayı amaçladım. Seyirciyi karşılaştıkları materyalle olan ilişkilerini birer 'tanık' olarak incelemelerini sağlayacak şekilde konumlandırmak istedim. Seyirci oyunda 'tanık' olmakla beraber oyunun 'hikayesine' de tanık olacak (Savran 2007: 27). Elizabeth LeCompte, bu konuda haksızlık yaşanmaması için Miller'a çalışmalarına dahil olması için teklif götürür ancak Miller bu teklifi geri çevirir. Sonuç alınamayınca grup Arthur Miller'e ait olan kısımları oyundan çıkarıp yerine Michael Kirby'nin The Hearing adlı oyununu ekler ancak bu meseleyi bir süre oyunda farklı şekilde kullanmayı da ısrarla sürdürür. Cadı Kazanı oyunundan kısa parçalar 
anlaşılmayacak kadar hızlı okunarak kullanılır, kelimeler anlaşılır olduğu anda sesli bir ikaz çalınarak oyuncu susturulur (Erickson 1990: 227). Görüldüğ̈̈ gibi burada da grubun yaşadığı süreç oyuna dahil edilir. Miller'ın suçlamaları ve LeCompte'un savunması hiçbir zaman mahkemeye kadar gitmez ve tartışmalar yıllardır metin ve performans arasındaki ilişkiyi irdeleyen çağdaş tiyatro kuramcılarını hayal kırıklığına uğratmakla yetinir.

\section{Oyunculuklar}

The Wooster Group, sıra dışı oyunlarında tanıdık simalarla çalışmıştır. Bu isimlerin başında meslek hayatı boyunca pek çok karaktere can veren Willem Dafoe gelir. Dafoe başta olmak üzere topluluktaki oyuncular karakterlerini kendi kimlik ve kişilikleriyle paralel bir çizgide oluşturur. Karakterlerin özünü oyuncunun kendisi oluşturur, yani karakter oyuncuya değil oyuncu karaktere etki eder. Dafoe bu etkiyi şu şekilde özetler:

\footnotetext{
Bir şey üzerinde çalıştı̆̆ımız zaman, oyuncuların hangi konularda iyi olduklarını ve olaya nasıl yaklaştıkların göz önünde bulundururuz. Herkesin belli bir işlevi vardır ve birbirimize değişim geçirmesi gereken oyuncular gözüyle bakmayız. Biz sadece Ron'un kendisi olarak oyuna kattıklarını alıp onu biçimlendirmekle yetiniriz. Ron kendisini olduğu gibi bize sunar. . . . Bu demek değildir ki Ron sadece kendisi olarak kalır, biz onun özelliklerini alır yoğurur ve belli bir yaprya oturturuz (Austlander 2002: 306-07).
}

The Wooster Group'un oyunları oyuncuların kişiliklerinden doğan karakterlerin etrafına inşa edilir. Topluluğun farklı yollarla farklı anlamlar üretme çabasını Dafoe'nun canlandırdığ1 karakterlerde de görürüz. Sinemada genellikle tehlikeli karakterleri canlandıran Dafoe, The Wooster Group'un oyunlarında düzenli olarak daha sakin ve hassas bir yapıyla karşımıza çıkar. Bu durum bir tesadüf değil, topluluğun kendi içinde karakter yaratma aşamasında edindiği bir çizgidir. Dafoe'nun sinemada alışılagelmiş sert duruşu, oyundaki hassas yapısıyla çatıştığı an, The Wooster Group sahnelediği oyunda istediği noktaya varmış olur. Dafoe'ya sinema yoluyla daha önceden yüklenmiş anlamlar, bu anlamlarla çelişen bir karakterle etkileşim yarattığ zaman Dafoe oyundaki gerçek işlevini tamamlamış olur (Austlander 2002: 306).

Oyuncuların karakterle olan interaktif bağı, izleyicinin oyuncu ve karakterle olan ilişkisini de muğlak bir duruma sokar. Bunun en ilginç örneklerinden biri Hula adlı oyunda karşımıza çıkar. Sahnede hula dansı yapılır ancak seyirci, bu dansı bir grup oyuncunun kendi keyifleri için mi yoksa oyun gereği mi yaptıkları konusunda kararsız kalır. Dans esnasında Dafoe'nun sık sık gülümsemesi, sanki herhangi bir yerde arkadaşlarıyla umursamadan dans ediyor havasında olması seyircinin aklında soru işaretleri bırakır. Örneğin kim gülümsüyordur? Danstan keyif alan Dafoe mu yoksa Dafoe'nun oynadığ1 dansçı mı? (Austlander 2002: 306). Kafalarda oluşan bu gibi sorular topluluğun oyuncu ve karakter arasındaki ince çizgiyle ne şekilde oynadığını ortaya koyar. Dafoe ise bu sorulara neden olan durumu kendi kişiliğinin bastırılmamasına ve sahne etkisine bağlar. Dafoe karakterlerin aslında kendi kişiliğinden olduğu kadar aksiyonla da canlandığını anlatmak ister. Karakterler önceden mutlak bir şekilde biçimlendirilmez. Hatta aynı oyunda Dafoe'nun canlandırdığı farklı karakterler arasında bir ayrım yapmak bile Dafoe'ya göre mümkün değildir. Örneğin L.S.D. birkaç katmandan oluşan bir oyundur. Birinci bölümde, oyuncular sadece bir kitabın bazı bölümlerini okurlar. İkinci bölümde ise Arthur Miller'ın Cadı Kazanı oyunundan bir kesit sahnelenir. Üçüncü ve son bölümde ise ikinci bölümün aynısı L.S.D. ilacının etkisi altındayken tekrarlanır. Dafoe bu üç ayrı bölüm arasında hiçbir ayrım yapmaz. Birinci bölümde kendisi olarak kitap okuyan, ikinci bölümde John Proctor 
karakteriyle sahneye çıkan ve üçüncü bölümde LSD etkisinde John Proctor olmaya çalışan Dafoe arasında bir fark aramaz. (Austlander 2002: 307). Ona göre her biri zaten tek bir kişidir:

John Proctor'ı asla düşünmem, sadece yapmam gereken konuşmanın nasıl bir etki yaratacağını değerlendiririm. Elbette 'burada biraz daha rahat olmalısın çünkü biraz daha dokunaklı bir sahne ya da Proctor bu sahnede iyi adam olmalı, diğer sahnede sinirlenmeli yetti artık' gibi önerileri dikkate alırım. Ancak 'o' zaten 'ben'imdir çünkü 'John Proctor' benim için hiçbir şey ifade etmez. Mış gibi yapmak ya da değişim geçirmek söz konusu değildir. John Proctor'ın birinci bölümde kitabını okuyan adamdan ya da üçüncü bölümde 'Hadi ama hangi cehennemdeyiz?' diyen adamdan farkı yoktur (Austlander 2002: 308).

Dafoe'nun aralarında ayrım yapmadığı karakterlerle olan ilişkisi, izleyici ile olan ilişkisinden tamamen farklıdır. Onun için oynadığı karakterin bilincinde olması, bir anlamda kendini oynarken izlemesi, izleyicinin onu izliyor olmasından daha önemlidir. Dafoe'ya göre oyuncu bu şekilde kendisiyle yüzleşir ve kendisini keşfeder.

Ne kadar sahneye çıkarsam o derecede izleyiciyle olan bağım kesiliyor ve kendimi izleyiciden daha da soyutluyorum. . . . Benim için bu tamamen kendi içimde geçen bir olay. Belli bir karaktere bürünsem bile, her zaman bu karakteri nasıl yarattı̆̆ımı, diğer insanların benim kim olduğum konusundaki fikirlerini, kendimin bile kim olduğunu merakla sorgularm. Tüm bunlara aksiyonu eklediğinizde kendinizle yüzleşirsiniz. Sizi hep başka bir odaya çıkaran açık bırakılmış bir kapı... Ben aslında hiç bir şey sunmuyorum sadece hissettiğim yolda yürüyorum. Ĕger bir şeyi oynuyorsanız ve bunu yaptığınızın farkındaysanız, bir noktada onu sinırlarsınız ve bitirirsiniz. Benim durumumda ise ne olacağı hiç belli olmaz (Austlander 2002: 307).

Daha geleneksel oyunculuk yöntemlerine kıyasla Dafoe'nun benimsediği yol oyuncunun ne olacağı belli olmayan sınırsız bir alanda dans etmesini sağlar. Dolayısıyla, The Wooster Group'un oyunlarında süreç ve sonuç birbirine bağlıdır. Oyuncular için performans, bir rolü yorumlamak değil, oyunu yaratma aşamasında karakterin geçirdiği değişim sürecini ve bu süreçte grubun verdiği kararları tekrar sahneye koymaktır. Oyuncunun izleyici tarafından algısı ve oyuncunun kendisini nereye koyduğu performansın bir parçasıdır ki bunlar genelde geleneksel oyunlarda karakter ve psikoloji gibi kavramlar adına geri plana itilmiştir. The Wooster Group bu konuları ön plana çıkarmakla kalmaz, bu kavramları oyunun konusu olarak da kullanır. Oyuncu, içinde bulunduğu durumu ve yerine getirdiği görevi keşfetmeye bırakılır. Bu keşif zaman zaman tepkilere neden olsa da, sinırları zorlayan bu yolculuklar The Wooster Group'un Amerika'da avangardın en önemli temsilcisi olmasını sağlamıştır. 


\section{SONUÇ}

The Wooster Group'un prova süreci, oyunu sahneleme aşaması ve oyunculukta benimsedikleri yöntemler, Jacques Derrida'nın yapısöküm yöntemiyle doğrudan örtüşmektedir. LeCompte, postmodern kuramcıları okumadığını iddia etse de, (Aronson 2000: 187) Derrida'nın etkisi topluluğun oyunlarında açık biçimde görülür. Arnold Aronson'a göre "grubun son çalışmaları yapısöküm kavramının Amerikan tiyatrosunda kullanıldığı yegâne örneklerdir" (Aronson 1985: 66). Stephen Bottoms ise topluluğun bilinen metinleri "yapısöküme uğratma konusunda ün saldığını" ifade eder (Bottoms 2004: 693). The Wooster Group'un bu konuda doğrudan bir açıklaması olmasa da, ekibin pek çok çalışmasında yapısöküm yönteminin etkilerini görmemek imkânsız. Derrida'nın 1966 yılında Structure, Sign and Play in the Discourse of the Human Sciences yazısında merkez kökenli düşünce yapısından kopuşu ile The Wooster Group'un oyunlara hazırlama süreci birebir aynıdır. Verilen örneklerde görüldüğü gibi her oyunda merkez kavramı sorunsallaştırılmış ve merkeze yaklaşıldığı an bundan bilinçli bir şekilde uzaklaşılmıştır. Bunu LeCompte şöyle örneklendirir: "Bir sahnede peş peşe gelen aksiyonlarn sonunda kriz doğuyordu. Biz de o sahneyi parçaladık. Çatışma, yüzleşme ve yatışmadan oluşan doğrusal yapıyı yok ettik. Yüzleşmenin birini başa aldık, yatışma anlarının arasına bir tane daha koyduk. . Yapıyı bozmuş olduk" (Aronson 1975: 34). Sakonnet Point, Rumstick Road ve L.S.D. oyunlarında bahsedildiği üzere topluluk oyunun yaratım aşamasında kullandıkları materyalleri (otobiyografi, obje ya da aktivite olsun) asla merkeze koymaz. Bu parçalar; farklı, değişken, hatta çelişkili anlamlar yüklendiklerinde işlevlerini yerine getirirler. Bu yüzden topluluk otobiyografiyi malzeme olarak kullandıkları oyunları belgesel olarak nitelendirmez, klasik eserleri kullandıkları oyunları da uyarlama olarak değerlendirmez. Bunlar oyundaki büyük ağın parçalarından sadece biridir ve diğer parçalarla bir araya geldikleri zaman sınırsız anlam seçenekleri yaratırlar. Ekibin bu yaklaşımı Derrida'nın bahsettiği anlamın sürekli olarak ertelendiği düşüncesiyle de örtüşür. Derrida sanıldığı gibi gösterenden bağımsız bir gösterilen olamayacağını ve her gösterilenin bizi bir başka gösterene götüreceğine işaret eder. Örneğin herhangi bir sözcüğün anlamını sözlükte baktığımızda karşımıza çıkan gösterge bizi başka bir göstergeye yöneltir ve bu süreç hiçbir zaman sonar ermez. Böylece sonsuz bir zincir oluşur. Göstergeler ile gösterilenler arasında sürekli bir hareketlilik mevcuttur. "Dilin bu akışkanlığı, kestirilemez gidiş ve gelişleri, anlamın gönderenden gönderilene ulaşması için sürdürülen girişimi sürekli erteler" (Barry 2002: 64). Bu akışkanlık The Wooster Group'un yukarıda bahsi geçen tüm performanslarında karşımıza çıkar. Oyunlar hiçbir zaman kesin ve net olarak sonuçlanmaz. Aynı oyun farklı temsillerde değişebilir, bir temsilden diğerine kendisini yeniler. Sürekli kabuk değiştiren bu yapının altında, daha önce örneklendirildiği üzere, topluluğun tüm süreci metin olarak kullanması yatar.

Bunun sonucunda her izleyici oyundaki bağlantıları farklı kurar. Dolayısıyla mükemmel bir izleyici ya da kusursuz bir "bütünlüğe" ulaşmış sanat eseri fikri geride bırakılır ve seyirciye farklı kapılar açan parçalar sunulur. Oyun "doğruları" ya da "gerçekleri" sunma çabasında değildir. Şüphe ve kararsızlık teşvik edilir. Amaç izleyiciyi bilgilendirmek ya da belli değerleri aşılamak değildir, tam tersi izleyiciye kendi inançları sorgulatılır. LeCompte, sanatı "ahlaki değerleri ya da insanlığa dair 'gerçekleri' dile getiren bir araç" olarak görmez (Marranca 2003: 14). Sahnelenen eser izleyicilerin yorumlarıly yeni anlamlar kazanarak kendisini gerçekleştirir. İzleyici karşısında objeler, metin ve oyuncular; birbirleriyle çarpışır dağılır ve tekrar bir araya gelir. Derrida, Batı felsefesinin ikili karşıtlıklar üzerine kurulu olduğunu, bu karşıtllkların belli bir değer hiyerarşisi 
oluşturduğunu ve bunun sonucunda bilinçdışı bir yapı geliştirdiğini ileri sürer. Derrida'nın yapısöküm yöntemi, ikili karşıtlıkların ters yüz edilmesi, metne gömülü çelişkilerin ortaya çıkarılmasıyla hiyerarşiyi yıkma işlemine dayanır. Böylece farkında olmadığımız ve metnin içinde barınan mevcut düşünce yapıları kırılır. Topluluğun klasik metinleri yorumlama biçimi de bu doğrultudadır. Arthur Miller'in Cadı Kazanı oyununun ele alınış biçimine bakarsak odak noktası sadece metin değildir. Topluluk L.S.D. oyununda Cadı Kazanı gibi klasik bir metnin yıllardır insanlarda oluşturduğu fikir ve düşünceleri sorgulamak ister. LeCompte bunu şöyle açıklar: "Seyircilerin pek çoğu bu oyunu ya okulda incelemiş ya bir tiyatro topluluğunda sahnelemiş ya da üniversitede sahnelenirken izlemiştir. Bu yüzden bu oyun seyircide farklı çağrışımlar yapmaktadır. Bu çă̆rışımlar benim mizansenim için önem taşır. Bu oyun iki kuşak için hem edebi hem de politik bir ikondur" (Savran 2007: 27). The Wooster Group insanlar1 çevrelemiş olan bilinçdışı etkileri ortaya koymak için bazen herkesin karşısında durmak zorunda kalmıştır, ancak hiçbir şeyi sorgulamaktan vazgeçmemiştir. Topluluğun yıllardır ortaya koyduğu provokatif eserleri en güzel Arnold Aronson betimler: Ve "sonuç modern bir şehri andırır, temelleri mirasçıları oldukları kültürlere dayanan bir şehir... Geçmişs şimdiyi desteklemeye devam eder, yeni eserden geçmişin tarihsel ağırlı̆̆ yankılanır ama yeni olan yine de emsalsizdir" (Aronson 1985: 67). Geçmişi yok saymayan, bugünün değerlerine saplanıp kalmayan, sıradanlaşmaya karşı inatçı bir direniştir The Wooster Group'un eserleri... 


\section{SUMMARY}

The Wooster Group is one of America's leading avant-garde theatre companies. There are many reasons behind their great achievements. First of all, they disregard old conventional rules. For example, the company never starts out with a fixed text. Everything that happens during the rehearsals can become part of their performance. All their members contribute to all aspects of their work's evolution. Their rehearsals are based on improvisations that start with an object, activity, or even an image. The plays develop through these improvisations. Even when they finish the rehearsals, they don't have a fixed text. Anything that happens during the production can change the course of the play. They create fluid texts that are always open to change.

The Wooster Group can be considered as one of the pioneers of aesthetic deconstruction since they have been known for their unique reworkings of well-known plays. They have deconstructed classical texts like Arthur Miller's The Crucible. They break down texts in order to find meanings that are not obvious at first. The new deconstructed text therefore interrogates the old one. Even though they had to deal with various accusations due to this method, they have never quit their exploration.

In all their performances the group is careful not to have a linear story line. When they realize they have one, they immediately break it up and create fragmentary stories. They disregard illusion and prize ambiguity. Unlike others, they don't have a desire to have a center or focal point, which is a key feature of Jacques Derrida's deconstruction. Each production is a nonlinear abstract aesthetic. Similar to Derrida's philosophy they abandon the idea of an absolute truth. Their aim is never to preach their audience or to give them a specific message. They interrogate particular ways of thinking over others. They destabilize fixed ideas and values by using classical texts which people are familiar with.

The group's approach to acting is also different than traditional modes of acting. The actors see themselves as creative artists rather than actors with fixed roles. Compared to more traditional methods of acting, The Wooster Group doesn't focus on transformation or believability. They create their persona from self-understanding. As can be seen, their ideas on text, performance and acting are not based on conventional rigid rules. They challenge deeply rooted rules on creating a play as well as classical understanding of acting. For more than thirty years, they have remained bravely creative and courageously rebellious.

SEFAD, 2017 (38): 139-150 


\section{KAYNAKÇA}

ARONSON, Arnold (1975). "Sakonnet Point". The Drama Review 19 (4): 27-35.

ARONSON, Arnold (1985). “The Wooster Group's 'L. S. D. (... Just the High Points...)”. The Drama Review 29 (2): 65-77.

ARONSON, Arnold (2000). American Avant-garde Theatre: a History. London: $\quad$ Routledge.

AUSTLANDER, Philip (2002). “Task and Vision: Willem Dafoe in LSD.". Acting (re)considered: Theories and Practices. ed. Philip Zarrilli, London: Routledge.

BARRY, Peter (2002). Beginning Theory: An Introduction to Literary and Cultural Theory. Manchester: Manchester UP.

BIERMAN, James (1979). “Three Places in Rhode Island”. The Drama Review 23 (1): 13-30.

BOTTOMS, Stephen J. (2004). "Poor Theatre: A Series of Simulacra (review)". Theatre Journal 56 (4): 693-695.

CHAMPAGNE, Lenora (1981). "Always Starting Anew: Elizabeth LeCompte". The Drama Review 25 (39): 19-28.

DUNKELBERG, Kermit (2005). "Confrontation, Simulation, Admiration: The Wooster Group's Poor Theater". TDR: The Drama Review 49 (3): 43-57.

ERICKSON, Jon (1990). “Appropriation and Transgression in Contemporary American Performance: The Wooster Group, Holly Hughes, and Karen Finley". Theatre Journal 42 (2): 225-236.

GRAY, Spalding (1978). "Playwright's Notes". Performing Arts Journal 3 (2): 87- 91.

GRAY, Spalding (1979). "About Three Places in Rhode Island”. The Drama Review 23 (1): 3142

MARRANCA, Bonnie (2003). "The Wooster Group: A Dictionary of Ideas". PAJ: A Journal of Performance and Art 25 (2): 1-18.

RABKIN, Gerald (1985). “Is There a Text on This Stage?". Performing Arts Journal 9 (2): 142159.

SAVRAN, David (1988). Breaking the Rules: The Wooster Group. New York: Theatre Communications Group.

SAVRAN, David (2005). "The Death of the Avantgarde". The Drama Review 49 (3): 10-42.

SAVRAN, David (2007). "The Wooster Group, Arthur Miller and The Crucible". in Bloom's Modern Critical Views: Arthur Miller. ed. Harold Bloom. New York: Chelsea House Publishers. 